\title{
Research on the Application of Mirror Materials in Contemporary Public Art
}

\author{
Siqun $\mathrm{Xie}^{1, *}$
}

\author{
${ }^{1}$ Shanghai Academy of Fine Arts, Shanghai University, Shanghai 200040, China \\ *Corresponding author. Email: xiesiqun@qq.com
}

\begin{abstract}
The application of mirror material in modern public art promotes the artistic atmosphere and urban artistic atmosphere of the urban public environment, highlights the unique personality and cultural characteristics of the city, and expresses the thoughts and feelings among people, natural environment and social environment. This paper will discuss the performance characteristics and artistic value of mirror materials in public art, and analyze how mirror materials promote the development of contemporary public art by combining with practical application cases.
\end{abstract}

Keywords: mirror material, interaction, public art, artistic value, spaces

\section{INTRODUCTION}

In the process of social development, with the improvement of material life quality, people begin to pursue spiritual and cultural satisfaction. The rapid development of science and technology constantly promotes the progress of civilization in modern society, and the public aesthetic consciousness is constantly improving. Compared with foreign developed countries, the level of spiritual and cultural construction in China has improved significantly, and the proposal of public art has made the public pay more attention to artistic expression and aesthetic appreciation. Public art is a kind of form symbol and form expression of contemporary artistic and cultural characteristics, and an art form that develops continuously in the context of urban culture. It is also an artistic form between man and environment, man and space, environment and society. Artistic creation or artistic expression in public space, adhering to the design goal of serving social groups, is the artistic mission of public art.

Because of its unique aesthetic value, perceived value and interactive value, mirror material is often selected as the main material of public installation art. Mirror material has the typical characteristics of optical reflection, using mirror material for public art design can transfer different design concepts and design value in a specific space. Art design of mirror materials at different angles or distances can produce rich artistic effects in public space and create visual and spatial feelings different from other materials. Public art can consolidate the artistic relationship between social public space and the public, and promote social progress and development. The public can feel the publicity and artistry of public art transmission through the interaction with mirror materials.

\section{AN OVERVIEW OF MIRROR MATERIAL}

The mirror material is a material for manufacturing an optical reflection mirror. Usually, a layer of material with good polishing performance (such as electroless nickel plating) is added to the surface, and then optical precision processing is carried out. The surface finish of the mirror material is high. Mirror materials have intuitive artistic expression effect, and can produce direct interactive value and perceived value with the public.

\section{A. Source of the mirror}

Eight thousand years ago, people in Anatolia (now Turkey) made the world's first mirrors out of polished obsidian. Ancient bronze mirrors have gradually evolved into modern daily glass mirrors through the continuous renewal of technology and raw materials. Silvered mirror material is the early main mirror material, with the development and progress of science and technology, there are aluminized mirror material and other different types of mirror materials with different functions.

\section{B. Types of mirror material}

The most common types of mirror materials are ordinary glass, metal materials, bronze, carbon fiber, fused silica and so on. Ordinary glass is mainly divided into hard glass, ship window glass and optical glass. It will also include colored glass, art glass and other types of glass; Metal materials include metal stainless steel, aluminum alloy, high light, tungsten steel and other materials, metal stainless steel processing time is longer than glass, coating can improve the reflectivity, can be used as strong laser reflector; Bronze can be directly 
ground and polished to make ancient bronze mirrors; Carbon fiber composite material is a more environmentally friendly mirror material, in order to pursue the concept of green design. At present, this mirror material is the first choice in some public installation art design; Fused quartz is also a typical glass. Fused quartz can crystallize during cooling to form regular quartz crystals, forming a controllable mirror material.

\section{Characteristics of the mirror material}

Mirror materials have extremely rich artistic expression characteristics, according to the physical characteristics, functional characteristics and interactive characteristics of mirror materials, the characteristics of mirror materials are summarized as follows:

1) Reflectivity: Reflection is the most basic physical characteristics of mirror materials, and it is also the most commonly used artistic expression of mirror materials in public art. Mirror material through the public space in the building, the surrounding ring and public reflection, so that the surrounding environment through the use of mirror in different angles to show a copy of the form of distortion or deformation of the artistic effect. Mirror reflection can bring people subjective visual illusion relationship extension, so that people through the mirror illusion effect of public devices on their own public environment and public art atmosphere for self-thinking and reflection. Reflection also has the artistic expression of exaggeration and distortion, reflecting the surrounding environment of public space on mirror materials, showing the opposite of the objective form of exaggeration or deformation, and causing the public's sense of difference and experience by deconstruction from different angles, breaking people's inherent cognition, and shaping a unique artistic form.

2) Practicability: Mirror material has strong extensibility in public space, and can create different spatial latitudes and spatial forms through the combination and splicing of different angles. To a certain extent, it can also blur the boundaries of space and give people the illusion of infinite space. Some mirror materials have long service life, lifelong use value, environmental protection and self-cleanliness. To some extent, mirror materials have the functional properties of energy saving and environmental protection, can absorb light energy under the irradiation of daily natural light, and will not cause harm to the natural environment and people's bodies. Indoor public space also has the function of brightening and heat preservation, which is convenient for staff to maintain and manage in the later period.
3) Interactivity: The mirror surface material has the decoration function, the different skin texture utilizes in the mirror surface material surface to be able through the reflection to appear the different artistic shape. Curved mirror can bring artistic temperament to public art design and enhance the artistic atmosphere of public space. When the public interacts with public installation art with mirror materials, they can feel the interaction between works of art and people. When the public enters the public space, they can intuitively interact with the works and the environment, which is also an interactive expression of "living art". While interacting with mirror materials, the public can produce subjective aesthetic cognition and aesthetic experience, which can provide psychological hints and psychological support for the public to a certain extent. In indoor public space, interactivity can also create a virtual three-dimensional optical illusion space through the placement of different angles of mirror materials, in which the audience can interact through optical illusion and sensory experience, so that the audience can more naturally integrate into the public space.

\section{THE VALUE OF MIRROR MATERIALS IN CONTEMPORARY PUBLIC ART DESIGN}

The public art design should have two characteristics: one is public, the public art exists in the place which the public may enter and exit freely, the people may freely appreciate and enjoy the artistic success which designs; Second, invasive, because it is set in an open public space as a visual object, whether the viewer is willing to accept it or not, it will inevitably enter people's vision 4.Contemporary public art creation is mainly a specific public space within the community as the main target audience, combined with the surrounding natural environment and social environment background analysis, select the creative material for artistic expression. Because of the typical reflective characteristics of mirror materials, they can perceive the interaction between the public environment and the viewer, and are usually selected as contemporary public art design materials. Mirror material in contemporary public art design can also reflect the use of the material of different dimensions of artistic value.

\section{A. Aesthetic value}

Place plays a decisive role in the positioning and design of public art installations. Time and space come together in a place, which contains metaphor and symbolism, can be very big or very small, can be a real point on the map, or can be fictional. Public works of art exist in the public nature of the site, the meaning and form of works rely on a specific display site, namely the site-specificity of works of art. "Field-specificity" 
does not only imply that a work exists in a certain place, nor does it mean that the work itself is a place. Rather, it means that the appearance and meaning of a work are largely determined by the configuration of the space in which it is realized. The site of a specific place, light source, location relationship will affect the viewer's visual senses at the visual level. Viewers will have different aesthetic evaluation criteria when they watch public installations with different mirror materials in different public environments. The audience's aesthetic appreciation of mirror materials will not only stay in the form, but also carry out subjective aesthetic thinking or aesthetic criticism on the content of reflection, so as to refresh their personal aesthetic standards, and then enhance their awareness of the beauty of social or urban environment.

\section{B. Value of interaction}

Mirror materials can interact directly with the audience because of their physical properties. When public art installations containing mirror materials are placed in public space, the public can see distorted or deformed self-portraits through mirrors. This form of interaction is an abstract artistic expression on the surface, and is essentially a dramatic way of presentation. Through the reflective characteristics of mirror materials, it can produce subjective visual illusion relationship, form visual depth and transparency, form virtual space mixed with reality in a certain form, mix the audience's understanding of space boundaries, and promote the audience's perception and interaction with light, shadow or devices in the mixed space. It establishes the multi-sensory interactive value between human beings and modern public art in the form of artistic expression.

\section{Perceived value}

Modern public art emphasizes artistic transmission and artistic perception, it usually combines with urban architecture or urban landscape, promotes the artistic atmosphere of urban public environment and urban artistic atmosphere, and promotes the ideological and emotional between people and natural environment, social environment. The social masses can get different information in many public art installations, because different public art materials have different information contents. When mirror materials are integrated into modern public art, viewers can directly perceive their artistic value through vision.

Modern public art is usually based on the natural environment as the creative background, the application of mirror materials can create the surrounding natural environment by mirror reflection, viewers can stand in different angles to feel the mirror materials reflect the artistic beauty of the natural environment. When the mirror material is applied in the mixed public space interior, the viewer can combine subjective vision, hearing, smell to feel the rich changes, in the space interior, the material form is easy to perceive the object, the viewer can perceive the mirror material in public space time and space illusion of artistic beauty. When the viewer returns to reality, this perceived value will be transferred to the real environment, prompting the viewer to consciously enhance the artistic perception of the urban environment.

\section{ANALYSIS ON THE APPLICATION OF THREE-MIRROR MATERIAL IN MODERN PUBLIC ART}

\section{A. Analysis on the application status of mirror materials in modern public art}

Mirror material is widely used in modern public art because of its special physical properties. Whether indoor public space or outdoor public space, as long as it has rich colors, strong light and shadow and broad natural environment, basically can see the application of mirror material elements. In urban public space, considering the urban public environment and urban cultural connotation, combined with the aesthetic characteristics of the social masses, through the choice of overall cutting mirror material as the expression form of public installation art. In indoor public space, due to the limitation of natural light source, usually combined with colored materials or artificial light source to splice the form of mirror material application. According to the current development process of modern public art, we usually choose mirror materials with color bias to create modern public art, enrich the urban public environment and urban art atmosphere, and use color expression to enhance the artistic perception of the public.

\section{B. Analysis of the application forms of mirror materials in modern public art}

1) Integral moulding: In the independent part modeling, glass, high-gloss metal, high-gloss acrylic and the like are subjected to hot melting, cooling, shaping, bending or laser cutting to form a part or an independent product 6 with the shape required by the design.

2) Combination and splicing: Mirror materials of the same material are cut into different shapes, combined and spliced according to the abstract artistic expression form, and the spatial form of the combination of reality and reality with perspective relationship is formed in public space. Because the combination and splicing of mirror materials have planar properties, the basic combination forms of points, lines and planes can also be used to repeat the composition in space, combined with their physical 
properties, to form a multi-dimensional visual space effect.

3) Refactoring and mashup: It is required to adjust the interior of the structure and express modern public art with mirror materials of different materials. In the case of ensuring that the information conveyed is understandable, more appropriate mirror materials are selected to reduce the cost of artistic creation and create modern public art with randomness.

\section{Analysis of the application form of mirror material in modern public art}

1) Visual expansion of art form: The unique visual effect of mirror materials can expand the space, and the reasonable use of mirror materials at the right angle can produce visual depth and breadth as well as penetration, forming a broader visual effect. The application forms of mirror materials are various, and the mirror materials of different materials can expand the space sense of the viewer's vision at different angles, forming an active space form. Through the inspiration application of the basic elements and combination rules of space modeling, various different forms can be created, mirrors placed in parallel can form repeated perspective space 7, and combination mirror materials with different angles can form different numbers of virtual image landscapes. The composition of this mirror material can provide visual extension for the form of expression of modern public art, and expand different visual forms based on the perspective of modern public art.

2) Visual dislocation of virtual and real space: In the reflection process of natural light source and material, mirror materials can obtain different visual effects from different observation angles. Based on this principle, some public installation works adopt the sensory principle of visual illusion to design different public art forms. This visual dislocation of the composition of the principle of mirror materials to show the real scene and the illusory scene integration constitute, combined into a new form of space, the formation of modern public art in the new space atmosphere. The illusory effect of mirror materials is a new artistic value pursued by modern public art, which creates a unique visual illusion experience for the masses of society.

3) Structural changes in public spaces: Modern public art pays attention to creating the diverse and rich environmental characteristics of public space, which needs to be based on the material relationship of different materials or the combination of virtual and real, find the close relationship between space and material through mirror materials, combine different angles and different materials of mirror combination, and produce new structural changes or structural forms in public space. Whether it is a virtual structure or a real structure, it can form a strong contrast relationship and increase the sense of spatial hierarchy. The reflection characteristics make the mirror device structure repeat and overlap, and then due to the change of angle and distance, the attenuation of visual effect is formed, thus forming the rhythm of gradual hierarchical structure in space, combined with the morphological performance of interleaving, facing and rotating, creating a richer structural relationship of space modeling 7. Mirror material creates a harmonious and unified space structure under the action of light source and color.

\section{A CASE STUDY ON THE APPLICATION OF FOUR MIRROR MATERIALS IN PUBLIC ART}

\section{A. Specular reflection-unreachable natural space}

Iranian artist Shirin Abedinirad placed a mirror installation in the ancient city of Persepolis, Iran. ("Fig. 1") The device chooses hard glass to wrap the middle part of the ancient city's stone street stairs, and the regular rectangular mirror stairs together with the ancient building itself create a symmetrical pattern as a whole. This arrangement refers to the symmetrical ladder layout in Islamic architecture.

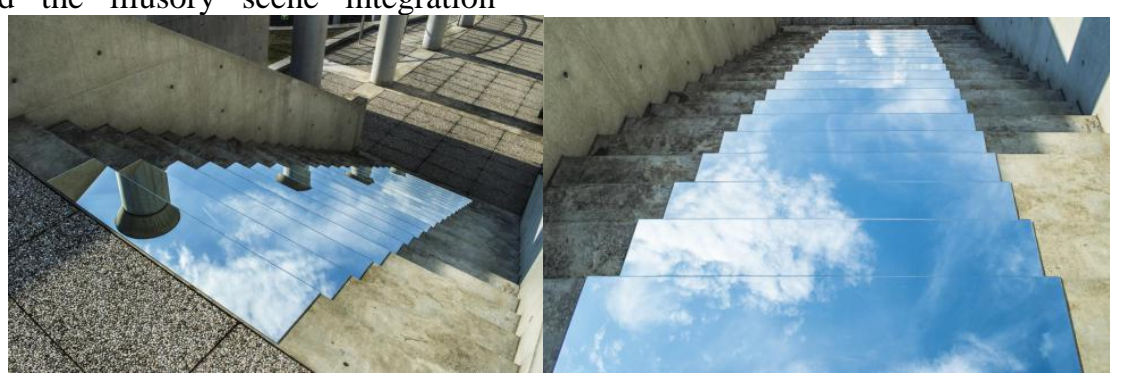

Fig. 1. "Heaven on Earth" public art works partial (source: network).

When the viewer stands at the bottom of the ladder, the mirror ladder he is facing can see the mirror image of himself constantly reconstructed in the hierarchy of the ladder. Walking up the steps, the viewer can see the 
mirror reflecting the constantly flowing sky. In the process of advancing from bottom to top, the viewer seems to enter the mirror image of the untouchable natural space, forming a visual fantasy of combining himself with the natural space, so that the viewer can experience the immersive natural space through behavioral interaction.

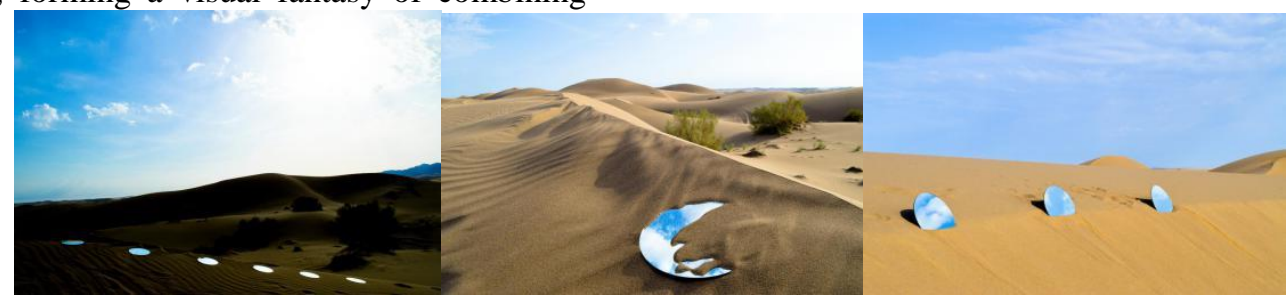

Fig. 2. "The Conjuring" public art works partial (source: network).

Shirin Abedinirad designed an installation called Conjuring in the desert of Tehran, Iran. As we all know, the first thorny problem facing the settlement in the desert is the lack of water. The device's circular mirror forms a pool of blue water in the desert, ("Fig. 2") which represents the ultimate mirage in the desert. When the golden sand covers the mirror, it looks like a small lake with a beach at first glance, bringing the audience the hope of "life" in the desert. But after a while the audience will realize that what they see is the sky, and gradually return to the objective reality.

Shirin Abedinirad uses simple mirrors with sand dunes and steps to create a contact with the sky. Through the natural flow of sand covering the mirror, a more natural "ecological landscape" is formed. This is also a kind of "living" modern public art expression, through the comparison of "water" and "sand", it evolves into an artistic comparison of "reality" and "unreality". Artists create a seemingly unrealistic space through mirror materials, but it is real, but it cannot touch.

\section{B. Mirror mix and match-interactive space of dynamic art}

In May 2008, artist William Pye designed a public art work in a new square near Oslo, Norway, called
Vannpaviljong. ("Fig. 3") This work chooses the mirror polishing of stainless steel as the main artistic expression material, and combines the flowing water wave dynamics to create a dynamic and static interaction mode of contemporary public art for the social masses.

From a distance, the work is a contemporary public art that can attract the eyes of the local people, when the audience interacts with the work, they can personally touch the external dynamic running water and spray water curtain, and from the running water, they can see the fuzzy self-mirror image. The interior space of the installation has led lighting and a double transparent dome is set up at the top, in which water is constantly flowing, and the application of different materials provides a form of expression for creating dynamic art. Audience can directly experience and enjoy various interactive effects inside and outside that device. In order to make the mirror material more artistic expression at night, combined with the lighting design of the square, we can see the hazy beauty of the city square reflected on the stainless steel mirror material after evening. The viewer can also enter the space and interact with the led lighting to see the self-reflection at different times.

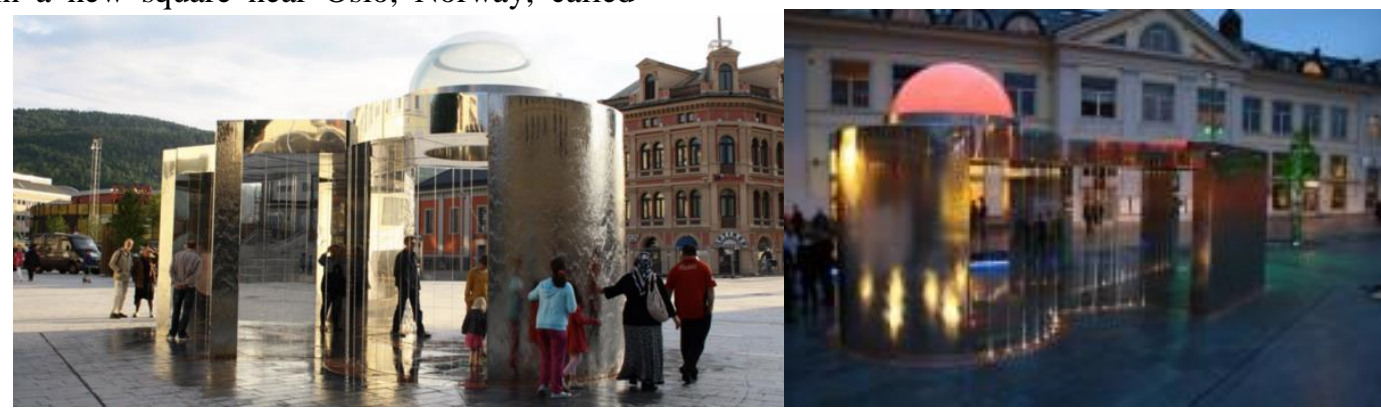

Fig. 3. Vannpaviljong public art work partial (source: network).

Water is also a kind of mirror material, which combines the mirror material of entity with the mirror material of ecological nature, takes the urban environment as the background of artistic creation, and conveys the dynamic art of contemporary public art to the social masses. Starting from the interactive 
experience between people and public installation art, we can create sustainable interactive value between people and urban environment.

\section{Mirror color-sensory experience of combination of light and shadow}

Installed in a seaside park in Alexandria, Mirror Mirror, a large-scale outdoor art installation created by British design studio SOFTlab, attracts people's attention with its colorful rainbows and unique mirror images. The installation is inspired by the lighthouse and uses an open circle to create the feeling between the people and the surroundings. ("Fig. 4") The device selects the Fresnel lens in the special lens as the expression material of the public art, and utilizes the section design of the corrugated to make the device reflect more light rays under the change of a natural light source in order to pursue the transmission range of light.

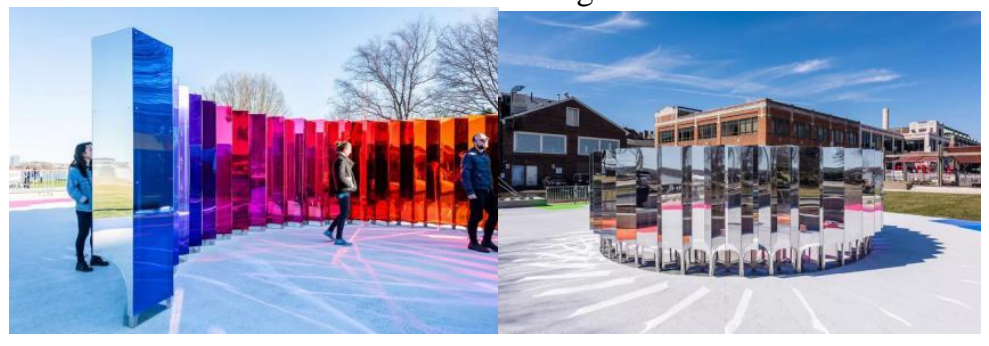

Fig. 4. Mirror Mirror public art works (source: network).

Through the reflection of the external environment, the reflection of the surrounding Alexandria Port, the old city and the park can be illuminated, and the local landscape can be integrated harmoniously and unobtrusively. The designer designs the inner mirror as a color mirror, with infinite colorful reflection and the forest of light as the creative concept, creating rich color art. When the local people enter the middle of the device, the led lights and sound devices in the internal color blocks will be activated, which can follow the interaction of the audience to produce sound and color transformation, and the external mirror will be converted into a transparent shell, forming a visual illusion sensory experience.

\section{CONCLUSION}

In urban construction, public art represents the level of urban civilization construction, but also represents the uniqueness of urban civilization and its unique logo. In contemporary public art, mirror material in contemporary public art has a very rich artistic expression, mirror material application is no longer a single material, but with a variety of different art materials combined with artistic expression. The artistic form of mirror material takes the natural environment or urban environment as the background of creation, combines natural light and shadow to create different color changes, angle changes and light changes, creates an interactive space where the virtual and the real intersect, and creates interactive experience to meet the different senses of the social masses. Through the artistic atmosphere of public installation art, the emotional connection between the local people and the social environment and the natural environment can be improved, and the artistic value of contemporary public art can be transmitted.

\section{References}

[1] Xie Siqun. Public Art: Creating "New" Value for Community Public Space [J]. Fashion Color, 2020 (9): 136-137.

[2] LI De-pei.Mirror materials [J]. Astronomical Research and Technology, 2008 (2): 167-175.

[3] Duan Hong.Reflection and Application of Mirror Material Effect in Space Design [D]. Changsha, Hunan Norma University, 2013.

[4] Chen Bing. The Characteristics and Making Principles of Contemporary Public Art Design [J]. Packaging Engineering, 2010 (16): 134-141.

[5] Jane Robertson et al. Themes of Contemporary Art: Visual Art after 1980 [M]. Translated by Kuang Xiao. Nanjing: Jiangsu Fine Arts Publishing House, 2015: 168-177.

[6] ZHang Hong-yu, CHen Shu-yun, Yan Min, ZHang Sheng-qing, ZHONG Shi-lu.Study on application of mirror material in American furniture [J]. Design Research, 2020 (1): 72-75, 91.

[7] Zeng Rong.Research on Space Form and Presentation in Mirror Installation Art [J]. Art Science and Technology, 2018 (3): 112166.

[8] Yang Guosong.Installation application of ceramic composite materials from the perspective of public art [J]. Art Appreciation, 2020 (2): 144-145. 